\title{
Living in Uncertain Times: Experiences of Menopause and Reproductive Aging
}

\author{
Heather Dillaway
}

While there is existing clinical and attitudinal research on reproductive aging, we often forget to focus on the phenomenological experience of perimenopause and menopause-that is, the lived, embodied, day-to-day experience of this reproductive and life course transition. This chapter will explore the everyday experience of women living and passing through perimenopause and menopause, a transition that involves many day-to-day uncertainties and changes, including definitional uncertainties, uncertainties about signs and symptoms, uncertainties about aging, and uncertainties about motherhood and changing relationship statuses. Because the hallmarks of perimenopause and menopause are uncertainty and change, I will argue that experiencing menopause and reproductive aging is akin to living in uncertain times, and learning to live in and with this uncertainty is part of the everyday experience of this reproductive and life course transition. In fact, acknowledging and owning this uncertainty could be a new and different way of approaching and thriving during this reproductive transition.

\section{Definitional UnCERTAINTIES}

Women often say they are "in menopause," but what does that really mean? What are perimenopause, menopause, and postmenopause, and how do women recognize that they are in these stages or phases of reproductive aging? What marks the start and end of this transition, clinically and experientially? The term "menopause" refers to the permanent cessation of menstruation and is typically defined by the final menstrual period (FMP) (Utz 2011). Clinical studies suggest that the average age of cessation is $48-52$ years of age, although women in Western countries end menstruation between their 
early 40s and late 50s (Mansfield et al. 2004). Menopause is caused by the fluctuation of hormone levels within the ovaries (Utz 2011). Despite popular belief, however, the decrease of estrogen hormones is not the sole cause of menstrual cessation; rather, many hormones fluctuate to cause this reproductive transition or "climacteric" (Fausto-Sterling 1992). These normal hormone fluctuations can occur anywhere from 8 to 10 years prior to cessation to several years afterwards (Fausto-Sterling 1992). What women experience is not just "menopause," then, but a complex reproductive aging transition that can sometimes span multiple decades.

Doctors and researchers commonly use a three-part clinical definition to make sense of women's experience of reproductive aging (Mansfield et al. 2004). According to clinical research and medical diagnosis guidelines, "menopause" is really defined by the lack of menstruation for 12 consecutive months and can only be defined in retrospect (Dillaway 2006). "Perimenopause" refers to the period leading up to menopause, and this is usually the time when signs or symptoms such as irregular bleeding, hot flashes, insomnia, and others may begin (Dillaway 2006). This stage is sometimes referred to as a "menopausal" stage simply because it precedes the time when a woman becomes menopausal (McElmurry and Huddleston 1991). This is likely why women may say they are "in menopause" when they are really in perimenopause. "Postmenopause" is the point after which a woman has not had a period for 12 months; often this stage is not diagnosed until one to two years after the cessation of periods (Dillaway 2006).

Women in their 40s and 50s in particular may find themselves wondering whether they have truly transitioned to perimenopause or reached menopause. Even after some signs and symptoms subside, women may ask, "Am I done or not?" (Dillaway and Burton 2011; Hyde et al. 2010). Moreover, all middle-aged women who menstruate may ask themselves and their doctors, "when will I be done?" Furthermore, when thinking about the stage or phase of reproductive aging that they might be "in," or "done with," women might make sense of their experiences differently than their doctors (even though they might rely on doctors for medical verification of their life stage [Hyde et al. 2010]). It is uncommon to hear individual women saying that they are "in postmenopause"; rather, they tend to say they are "done with menopause" during this stage. Or, in perimenopause, women might colloquially say they are "in the middle of menopause" (Dillaway and Burton 2011). Thus, women's language about this transition might vary from doctors' or researchers' language, and this sometimes makes it complicated for both women and doctors to understand each other. It is typically perimenopause that women are most concerned with, and women are often wondering when perimenopause will end. Nonetheless, one of the other definitional uncertainties for women is when perimenopause starts.

Some researchers have suggested that perimenopause begins when there is at least seven days in variability between one menstrual cycle and 
the next, then progresses to a separate stage characterized by skipped periods (at least a 60-day gap), and finally ends at 12 months past the FMP (for example, Harlow et al. 2008). However, Prior (2005) proposed instead that perimenopause can begin with symptomatic experiences like hot flashes and increased breast tenderness, and argued that because subjective changes precede menstrual irregularity women may initially find hot flashes and breast tenderness (as well as other signs and symptoms) just as problematic as changes in menstrual flow. Individual women also might not recognize clear transitions from one menopausal stage to another (Dillaway and Burton 2011). In a longitudinal study of 100 women, for instance, some women reported experiencing one stage for numerous years and then moving on quickly, but others reported flip-flopping between stages over many years (Mansfield et al. 2004). Flip-flopping between these stages can be quite confusing for individual women (Dillaway and Burton 2011). In Mansfield et al.'s study, though, one group of women progressed quickly through all three stages (Mansfield et al. 2004, 225).

Clinical definitions do not capture the variability in how women define reproductive aging for themselves, or how they experience the signs and symptoms of perimenopause, menopause, and postmenopause. Because of the focus on physiology only, existing clinical definitions of menopause are therefore partial at best. Social science and feminist researchers have suggested that women's personal definitions of reproductive aging-that is, how a woman herself recognizes, defines, and copes with her own experience of perimenopause, menopause, and postmenopause-are just as, if not more, important (for example, Dare 2011; Kafanelis et al. 2009). In fact, when individual women suggest that they are "in" menopause, this language validates women's experience of reproductive aging or perimenopause as a life stage, not just a retrospective moment or clinical diagnosis. Women's recognition that they live "in" an uncertain midlife reproductive stage (that is ill-defined for them at the current time) can be as helpful to their management of day-to-day signs and symptoms as the three-part clinical definition that remains static and often only retrospective. That is, women desire information that will help them understand their own day-to-day navigation of reproductive aging and its associated signs and symptoms. Broadening the working understanding of perimenopause, menopause, and postmenopause to include information on uncertain beginnings and ends, and varying signs and symptoms, means taking women's subjective experience of their reproductive bodies and midlife stages more seriously (Dillaway and Burton 2011). If we listen to women's discussions of being "in" this life stage, and living in uncertainty, then both clinical interventions and women's understanding of their day-to-day signs and symptoms could align better with women's experiences and needs. 


\section{Uncertainty Around Signs And Symptoms}

Defining the signs and symptoms of menopausal transitions has also proven difficult for clinicians and researchers, which makes for even more ambiguity for individual women. Medical websites and other authoritative sources, as well as women themselves, often attribute symptoms to perimenopause, including but not limited to mood changes, memory problems, fatigue, hot flashes (or flushes, depending on what country a woman lives in), insomnia, vaginal dryness, changes in libido, weight gain, hair growth, heart palpitations, headaches, and joint pain (for example, Avis et al. 2001). Indeed, more than 100 symptoms have been attributed to menopause (Cobb 1993; Fausto-Sterling 1992). Epidemiological studies have not found evidence of universal perimenopausal symptoms, however (Avis et al. 2001). Only bleeding changes, hot flashes, vaginal dryness, and insomnia are more frequently reported by perimenopausal and/or menopausal women, as compared with premenopausal women (Derry and Dillaway 2013). In Europe and the United States, approximately $70 \%$ of women will experience a hot flash (or flush) during perimenopause (Ayers, Forshaw, and Hunter 2010).

Epidemiological and social science research suggests that perhaps we blame more on perimenopause and menopause than we should (for example, Fausto-Sterling 1992) and that there may be very few bodily symptoms that can be tied specifically to menopause (and not, instead, to other life situations at midlife, lifestyle behaviors, or chronic conditions across women's life course). For instance, in a study of insomnia at perimenopause, Vigeta et al. (2012) found that many women who reported an increase in sleep disturbance in perimenopause also reported insomnia in earlier life stages. It was only after the effects of insomnia were more noticeable in their daily lives (at midlife) that they sought medical treatment for this symptom (Vigeta et al. 2012). Muhlbauer and Chrisler (2007) additionally suggested that vaginal dryness may simply indicate that women's bodies are not ready for sexual intercourse and that women take longer to become moist as they grow older; thus, vaginal dryness is neither a permanent condition for most middle-aged women, nor is it always directly attributable to menopause. Decreased sex drive may also be attributed to stress, fatigue, and over-burden at midlife, a time when women face multiple and overlapping responsibilities. Uncertainty around the attribution of symptoms to reproductive aging can be difficult for women as they attempt to evaluate and make sense of midlife experiences.

Women also have varied reactions to the potential signs and symptoms of certain stages of reproductive aging, and lack complete information about what signs or symptoms are like on a daily basis. For example, while biomedical studies describe the physiology of hot flashes, little is known about what individual women actually feel when hot flashes occur or how they affect their everyday lives. Because hot flashes can challenge norms about beauty and bodily control and sometimes alert others to women's menopausal status before women themselves are ready to disclose it (Dillaway 2011), individual 
women surely negotiate and think about hot flashes differently (especially when they happen in public settings). In particular, women may find hot flashes problematic in paid work settings and, depending on the type of paid work they do, they may define hot flashes negatively if they must negotiate them in front of coworkers (Dillaway 2011). Depending on the severity of a hot flash, women might need to attend to sweating, flushed skin, and the removal of layers of clothing, for instance, in the middle of a meeting or while cashing out a customer at a retail store. Depending on who is present during that hot flash an individual woman may feel stigmatized for the public nature of that symptom, or worry about whether others are thinking negatively about her while she is dealing with it (Dillaway 2011). Also at home, within family settings, male partners especially, but also children at times, become exasperated with women's "uncontrollable" bodies. Individual women must therefore handle others' perceptions of some signs and symptoms, which may make the individual experience of perimenopausal symptoms even more complicated (Dillaway 2011).

Biomedical definitions of "symptoms" are often purely negative, even pathological (Martin 1992). For instance, medical doctors often think of menopause as a cluster of symptoms caused by a "deficiency" in reproductive hormones (Lyons and Griffin 2003; Meyer 2003; Niland and Lyons 2011; Utz 2011). Ovarian failure and a deficiency of reproductive hormones are seen as the biological causes of any physical, physiological, or psychological changes during this time of life, and these changes are typically defined as negative (Lyons and Griffin 2003; Meyer 2003; Niland and Lyons 2011). This focus on biology eventually leads medical professionals to feel responsible for fixing women's "deteriorating" bodies and simultaneously encourages women to seek medical treatment to "replace" or "restore" their hormones (Martin 1992, 26; see also Meyer 2003; Niland and Lyons 2011).

However, research shows that women's subjective experience of these signs and symptoms are not always purely negative. Women may have many positive or neutral responses to symptoms. For instance, women in their $40 \mathrm{~s}$ and 50s may have teenaged daughters who are just reaching menarche, and having irregular periods alongside daughters may be an opportunity to bond (Dillaway 2005a). Depending on the exact severity of hot flashes, individual women may also take the opportunity to define this symptom as simply their own "private summer" (Dillaway 2011). Not all bodily signs or symptoms represent physical decline, even if those signs or symptoms do cause hassle or uncertainty at times. Furthermore, women's previous reproductive experiences have prepared them well for how to handle both expected and unexpected bodily signs and symptoms. Upon reaching perimenopause, for instance, women who have menstruated are already accustomed to experiencing bodily signs and symptoms associated with menstrual cycles. Therefore, because menstruating women have learned to notice, wait for, track, monitor, and manage reproductive signs and symptoms for the entirety of their adolescent and adult lifetimes, the arrival of new and/or adjusted signs and 
symptoms at midlife may not startle women as much as clinicians might expect or suggest. Bodily changes also may happen gradually in many cases, giving women time to contemplate and adjust to their new life stage. On the other hand, adjusting to slightly new signs and symptoms can be difficult on a daily basis and, in some cases, the severity of midlife bodily changes may lead women to visits their doctors for relief. Women may have a range of reactions, attitudes, and experiences with the signs and symptoms of reproductive aging: some negative, some positive, some neutral, and some confusing, and one sign or symptom may bring forth multiple reactions, attitudes, and experiences. On the one hand, skipping a menstrual period may feel freeing but, on the other hand, it may induce anxiety. Likewise, having a hot flash may be embarrassing in public the first time, but one may learn quickly how to navigate public reactions and adjust diet and clothing in order to moderate this physical sign or symptom. In these cases, an initial reaction to a bodily sign or symptom might be positive or negative, but reactions, attitudes, and experiences may adjust over time (Dillaway 2005a, 2011).

Social science researchers have even proposed that menopausal symptoms are more the result of sociocultural attitudes and ideologies than of biology. Lock (1993) made this clear in her comparative study of menopausal women in North America and Japan. She found that "menopause is neither fact nor universal event but an experience that we must interpret in context" (370). For example, whereas North American ideology idealizes youth, this is not the case in Japan, where "middle-aged" individuals actually form the "backbone" of society, "support[ing] both old and young, keep[ing] the economy growing and build[ing] the new Japan - men and women alike" (370). Constricting gender ideology does exist in Japan, of course, but Japanese women conceptualize the life cycle as "part of a larger cyclical continuum rather than as a path of no return that fragments youth from age" (Lock 1993, 378). In support of the social construction of reproductive aging, Lock found fewer reports of symptoms, such as hot flashes, among Japanese women. Other anthropological studies suggest that increased medicalization of menopause in North America leads to more negative views among individual women in that setting as well (Lock 1993). Yet, even within North American countries, there is more variation in women's symptom experiences than we typically acknowledge.

Lock (1993) and Utz (2011) describe "local biologies," in which women think about and experience physical or physiological changes at midlife differently, depending on their expectations for reproductive aging, their knowledge about this transition, and other psychosocial life contexts. How women think about signs and symptoms must contextualized within their other life circumstances and social locations, and no two women may think about or experience signs or symptoms in the same way. Some feminist scholars have gone further and recognized that menopause is more than just a collection of uncomfortable signs and symptoms and is instead, at minimum, a neutral, and often even a positive life transition (Dillaway 2005a; Lyons and 
Griffin 2003). For instance, women may welcome menopause as relief from the threat of pregnancy and the burdens of menstruation and contraception (Dillaway 2005a). The Baby Boomers are the first generation to have had widespread access to the birth control pill and other advances in contraceptive technologies that enable women to avoid biological motherhood (Dillaway 2005a). Contemporary women, then, may elect to end their reproductive years long before menopause. Within this context, menopause may be quite positive for many individuals. Regardless of the bodily changes they may face during menopause, then, individuals may view menopause as ushering in a "good" life stage, one that is better and more carefree than the one before it.

If we acknowledge women's vast experience with bodily signs and symptoms, we can recognize the limitless and varied reflections and responses to bodily moments and life course stages like reproductive aging. Signs and symptoms of perimenopause, menopause and postmenopause, as clinically defined, do not always represent the same thing for every woman, nor do they automatically signify deficit or decline. Living in and through the signs and symptoms of reproductive aging may indeed bring uncertainty for all, especially at the outset, and induce physical discomfort for some as well. Nonetheless, living in and through signs and symptoms may also introduce healthy and reflective adjustments to a new life stage.

\section{Uncertainties About Aging}

Whether or not women equate menopause with aging is also important for how individual women will view and experience menopause as a transition. Hall (1999) described an interview she conducted with one menopausal woman who explained,

Those night sweats—and other symptoms I began to notice-suddenly made me feel old. One day I'm a young woman in her prime, and the next day I'm worrying about whether or not I'm prepared for retirement and thinking about getting my affairs in order. (17-18)

Because of its conflation with chronological aging, the onset of menopause may have resembled a "death sentence" for many women in the past (Dillaway 2006). A widely held misconception continues to exist that all women used to die before menopause, and thus postmenopausal women are currently living beyond what nature prescribes (Weed 1999). Even if menopause is not a death sentence in our imaginations anymore, we are still confronted with a reiteration of the idea that "old guys can be gorgeous, but old women pollute the landscape, so mask them, keep their 'decay' out of sight" (Gray 1996, 186). The message is that women lose their "feminine," "healthy," and "sexy" attributes in midlife, and begin a continual decline after that. "After 50," women supposedly take on "the grandma look [becoming] 
women in buns, girdles, and orthopedic shoes" (Jarrell 1999, 2; see also Utz 2011). This situation arises directly from the fusion of a sexist and ageist culture, one that insists on viewing "older" people as "ill" or "sick" (Zones 2005) and women primarily as "mothers" (and, if not mothers, then sex objects) (Dillaway 2005b).

The image of femininity is primarily associated with youth, physical beauty, fertility, and reproductive capabilities in Western industrialized countries (Brooks 2010; Wilson 1966; Winterich 2007). Women may therefore believe that bodily changes must be slowed down or halted; gray hair, wrinkles, dentures, age spots, drowsiness, thickening of the waistline, sagging abdomens and breasts, sagging muscles, or crinkling skin, and bifocal glasses may seriously challenge one's gendered self-identity (Brooks 2010; Berkun 1986; Dillaway 2005b; Grambs 1989; Winterich 2007; Zones 2005). Women have been taught since girlhood to control their bodies (Dillaway 2005b; Zones 2005), especially around others who might gaze upon their bodies, which could make menopause and other midlife bodily changes anxiety producing. The fear of "being let down by their bodies if they must maneuver in a world that favors youth" may be strong (Berkun 1986, 383; see also Dillaway 2005b).

On the other hand, age-based norms are changing as Baby Boomers age. For example, Baby Boomers may identify and behave in the same ways they did when they were chronologically younger. For example, they participate in similar leisure activities, wear similar clothing, and are as physically and socially active as they were in younger years (Featherstone and Hepworth 1991). As a result, some scholars now suggest that there is no current cultural consensus about what it means to be a midlife, mature, or menopausal woman and women no longer routinely report feeling old at midlife (Dillaway 2005a). Changing norms may leave room for middle-aged women to feel and act the same as they did in previous life stages.

In addition, women are increasingly in the paid labor force and have other meaningful social roles during midlife, so that menopause has less potency as a cultural marker of entry into a negative life stage. In fact, menopause may parallel women's greatest accomplishments in paid work in contemporary times. "Aging" stars (for example, Meryl Streep, Helen Mirren, or Diane Keaton) or "older" women in politics (for example, Hillary Clinton or Maxine Waters) call into question the idea that "older" women are merely stereotypical grandmothers who are past their prime (Dinnerstein and Weitz 1994; Featherstone and Hepworth 1991; Muhlbauer and Chrisler 2007). Thus, they may experience chronological aging or reproductive aging (or both) as less stressful and more representative of new possibilities than previous generations did. Self-esteem for contemporary middle-aged and older women may not only depend on physical appearance and biology, but also on non-reproductive and non-familial accomplishments-as is the case for men. Grambs (1989) argued that these developments make the current cohort of 
menopausal women more positive about experiences of reproductive aging than previous generations of women who had fewer opportunities outside the home.

The disruption of the equation of aging and gendered decline may lessen women's negative attitudes toward menopause and decrease some of women's attention to negative bodily experiences. Women can also be thankful to move past menstruation, the use of contraception or birth control, the threat of pregnancy, and other gendered hassles associated with managing their earlier reproductive lives. The sexual and reproductive freedoms gained via menopause (such as discontinuing birth control use) may be particularly poignant for Baby Boomer women, who lived through the fights for access to birth control and abortion, as well as paid parental leave, daycare, and other sexual freedoms (Dillaway 2005a). Furthermore, not having to buy pads, tampons, and other menstrual supplies anymore, or wearing white underwear whenever one desires can be liberating. Additionally, women sometimes find that other midlife health events, such as getting bifocals or having back pain, make them feel "older" than the onset of perimenopause or menopause. In this way, reaching menopause may be reaching a "good old" rather than the "bad old" that is signified by other health transitions (Dillaway 2005a). While women who have experienced reproductive difficulties (such as infertility or miscarriage) may feel extremely negative about losing their reproductive capacity, others may feel empowered to move beyond daily reproductive burdens.

Menopause and midlife is still a time when women's identities and experiences shift. Women may still "feel young" (or, at the very least, "not old yet") but they may still recognize that their bodily and other social transitions are marking a new life stage for them. Aging is something that is both revered and feared, and it is a process that seemingly speeds up in midlife. Midlife also brings other life transitions, such as adult children leaving the home, the death of parents, greater likelihood of chronic bodily conditions, and possibly retirement. Ageism may continue to result in middle-aged women or men watching younger coworkers receive promotions in paid work, instead of them. Thus aging is still a context that women might define as negative in part, even if they are positive or indifferent about reproductive aging. Reproductive aging can be seen as unique from other kinds of aging in its possibilities, however. Reproductive aging represents as much of an opportunity for freedom as for burden. Moving beyond reproductive capacity while still feeling young can mean making one's debut into uncertain and uncharted territory, yet territory that is less confined by gendered cultural norms that women have the power to make their own. Many other cultures have shown us that women can grow into their own power as they age out of reproductive capacity (Lock 1993), and the lessening of age-based norms in North America has also strengthened this possibility for women in the United States. 


\section{Uncertainties About Motherhood and Relationships}

Family contexts can make the menopausal transition seem neutral, positive, or negative. For instance, women at midlife are often caring for elderly parents, partners, and children (often simultaneously); menopause can pale in importance to these caregiving responsibilities (Dare 2011). Women told Winterich and Umberson $(1999,61)$ that menopause was "last on [their] list" of things to worry about and "no big deal" in the context of other family problems (for example, divorce, children "acting out," or family death) (see also Dillaway 2005a, 2012). Dare (2011) also found that experiences of divorce, and the aging and death of parents weighed much more heavily on women than menopause. Thus, family contexts can make women feel neutral or positive about menopause. Bodily change may be noticed but might not be something for which women take time to seek medical help, given their busy and complicated family lives.

Menopause may seem more negative, however, in certain family contexts. Mansfield, Koch, and Gierach (2003) reported that husbands sometimes have negative views of menopause and/or know little about the experience overall. Even husbands who want to be supportive lack the information to be so or feel unsure about how to help (Mansfield, Koch, and Gierach 2003). Further, women sometimes want to share menopause experiences with their partners, but they avoid doing so because it is "a private thing" (Walter 2000, 117). Similar to what Fahs (2011) sounds about women's and partners' discomforts around having sex during menstruation, perimenopausal women have reported discomfort in talking with partners about perimenopausal signs and symptoms (Dillaway 2008). Due to a lack of information about menopause and women's reticence about sharing experiences, husbands' interactions with wives potentially cement negative meanings about menopause and encourage women to think about menopause as a collection of treatable symptoms.

We do know from previous research on social support that the older women are, the less support they receive from their spouses (Schwarzer and Gutierrez-Dona 2005). Partners can be supportive during other reproductive events (for example, pregnancy, birth, breastfeeding) but, because more secrecy surrounds menopause, Mansfield, Koch, and Gierach (2003) suggested that male partners may be less supportive at midlife than at previous stages (if only because they lack information about how to help). Further, because menopause sometimes remains invisible (or appears intangible) to others, partners and other family members may also not "see" reproductive aging as something with which to engage (unlike pregnancy, for instance, which typically results in publicly changing body and baby). Finally, lingering cultural views associating women with reproduction may make talking about menopause awkward, when it seems to represent an end to one of women's gendered roles (Dillaway 2008, 2012; Dinnerstein and Weitz 1994).

Negative images of menopause (and/or a lack of support for women at menopause) within families may affect women in adverse ways, lead them 
to internalize negative views, and incline them toward a medicalized view of menopause (Mansfield, Koch, and Gierach 2003). In this case, individual women may turn to medical relief for symptoms in order to appease intimate partners or important others. On the other hand, we know that sharing health experiences with intimate partners leads to better physical and emotional well-being (Mansfield, Koch, and Gierach 2003; Reid 2004; Walter 2000). "Women who are moving through the menopausal transition, even those who experience few adverse physical or emotional changes, still need to negotiate a change in status or a 'redefinition of self,' and married women may benefit from social support provided by their husbands during this transition" (Mansfield, Koch, and Gierach 2003, 103). Sharing health experiences in a positive way can increase individuals' reports of relationship satisfaction as well (Reid 2004), as family relationships are molded alongside health experiences.

In addition, however, perimenopausal women often rethink how they feel about intimacy and relationships. They may be on their own for the first time at midlife (because of divorce, widowhood, and empty-nesting), or they may finally be willing to end old or begin new relationships at this life stage. Those in new relationships may worry that menopausal status may deter others' interest in them, while others may feel much more "free" to engage in intimacy upon menopause (because of the lack of the threat of pregnancy). In sum, it is during this reproductive transition that many women may reconsider and question their motherhood and relationship statuses, and rethink their identities related to these statuses as well. This makes midlife and reproductive aging uncertain times for some women; in other cases, women might actually feel more certain about their identities than in any earlier period of their lives.

\section{Reproductive Histories}

Menopause can be neutral, positive, or negative for women as a result of earlier reproductive difficulties and reproductive histories. Women's feelings about menopause also cannot be separated from decisions that they and their partners make about whether to become parents. In some cases, menopause may take on more negative meanings, as seen in trends toward delayed childbearing and rising concerns about infertility (Dillaway 2012). Loss of fertility may be an important issue for a woman who has delayed childbearing until her 30s or 40s and then discovers that she has trouble conceiving. These women do not want to be finished with childbearing, either emotionally or in terms of life goals, and may feel that menopause has robbed them of their final chance to become biological parents. Conversely, coping with menopause may not seem as difficult as coping with infertility or miscarriage, and menopause may be a relief for a woman with a long history of difficulty becoming pregnant, who now has closure and can put decisions about infertility treatment and hopes for a family to rest (Dillaway 2012). 
Other women may have never actively or consciously made the decision to stop having children (even if, for example, it has been more than 10 or 15 years since their youngest child was born). For these latter women, the onset of menopause may make it feel like they never had the choice to finalize their decision themselves - the onset of menopause took that final decision out of their hands (Dillaway 2012). This may happen in situations where women may have prioritized their careers and birthed a first child "late," in their late 30 s or early 40s, for instance. Women with one biological child (or even two) may find themselves wishing they had had an additional child. In cases of divorce and remarriage, or delayed first marriage (especially if a new intimate partner desires children), menopause may also induce women's regret around the size of their families.

Regardless of women's exact feelings about reproductive aging, menopause does symbolize an end of their physical capacity to reproduce. While most women do not equate the end of fertility with menopause any longer (with the availability of contraception, fertility typically "ends" much earlier in contemporary times), women still often use this life course stage to recontemplate their motherhood status. Some women wish they had had more children, or that they could have had children at all. Women for whom motherhood was primary in importance may mourn the passing of stages of active caregiving. Others contemplate the relative lack of importance of motherhood in their lives, and see menopause as insignificant as a result. This means that women have wide-ranging responses to reproductive aging depending on their motherhood and family statuses. Unless we understand women's perceptions and experiences of menopause within the context of their choices and experiences around childbearing and childrearing, we cannot understand women's perceptions and experiences of reproductive aging. Because of women's mixed experiences of motherhood and family, experiences of reproductive aging will also vary. Individual women must find out for themselves how their reproductive histories might affect their perceptions and experiences of reproductive aging.

\section{Uncertainty and Change Is Normal at This Life Stage}

Regardless of how women feel about reproductive aging as a life course transition, there is no doubt that perimenopause and/or menopause involves biopsychosocial changes that women must navigate. Generally, then, this life stage brings both physical change and identity change. Because change can bring uncertainty, coping with uncertainty also becomes part of the everyday experience of reproductive aging (Kafanelis et al. 2009). Living through change can be good or bad or both, depending on women's perspectives and other life contexts. As outlined above, many of the uncertainties that women face can be attributed to confusion around the definitions of perimenopause and menopause, the uncertain signs and symptoms of this transition, uncertain feelings about aging, and reflections about motherhood and family experiences. 
Bodily change, alongside other life course and identity changes, can be defined in varying ways by women, which means it is difficult to define the impact of reproductive aging on women in any uniform or standardized way. Women may feel very much in flux during this life stage. Perhaps this means that we need to talk more about the fact that this feeling of flux and uncertainty is actually normal and natural during reproductive aging. Learning that uncertainty and change are the hallmarks of reproductive aging experiences may be uniquely satisfying and validating to individual women living in this transition. In fact, acknowledging and welcoming this uncertainty could be a bold and different way of approaching and thriving during this inevitable transition. All women who reach midlife have already lived through considerable change and uncertainty - a lifetime of reproductive experiences alone have accustomed women to change and uncertainty. Understanding that this life stage simply represents an additional time for reflection and a new bodily challenge could be healthy and freeing. As our bodies find their "new normal" through reproductive aging, we are free to think about this time in the way that suits us best. Instead of confining ourselves to thinking about menopause and reproductive aging through a biomedical lens, we can think of this life stage more broadly, as a chance to redefine ourselves and our bodies one more time. Thinking about ourselves as living in this uncertain time necessarily, rather than just getting through it, may be the first step to understanding and owning the impact of menopause and reproductive aging. Individual women, as well as women as a whole, can make what they want of this uncertain time.

\section{REFERENCES}

Avis, Nancy E., Rebecca Stellato, Sybil Crawford, Joyce Bromberger, Patricia Ganz, Virginia Cain, and Marjoria Kagawa-Singer. 2001. "Is There a Menopausal Syndrome? Menopausal Status and Symptoms across Racial/Ethnic Groups." Social Science and Medicine 52: 345-56.

Ayers, Beverley, Mark Forshaw, and Myra S. Hunter. 2010. "The Impact of Attitudes towards the Menopause on Women's Symptom Experience: A Systematic Review.” Maturitas 65: 28-36.

Berkun, Cleo S. 1986. "On Behalf of Women Over 40: Understanding the Importance of the Menopause." Social Work 31 (5): 378-84.

Brooks, Abigail T. 2010. "Aesthetic Anti-Ageing Surgery and Technology: Women's Friend or Foe?" Sociology of Health \& Illness 32: 238-57.

Cobb, Janine O. 1993. Understanding Menopause. New York: Penguin.

Dare, Julia S. 2011. "Transitions in Midlife Women's Lives: Contemporary Experiences." Healthcare for Women International 32 (2): 111-33.

Derry, Paula, and Heather Dillaway. 2013. "Rethinking Menopause." In Women's Health Psychology, edited by Mary Spiers, Pamela Geller, and Jacqueline Kloss, 440-66. Hoboken, NJ: Wiley.

Dillaway, Heather. 2005a. "Menopause Is the 'Good Old': Women's Thoughts about Reproductive Aging." Gender e Society 19 (3): 398-417.

. 2005b. "(Un)Changing Menopausal Bodies: How Women Think and Act in the Face of a Reproductive Transition and Gendered Beauty Ideals." Sex Roles 53 (1-2): 1-17. 
2006. "When Does Menopause Occur, and How Long Does It Last? Wrestling with Age- and Time-Based Conceptualizations of Reproductive Aging." Feminist Formations 18 (1): 31-60.

- 2008. "'Why Can't You Control This?" Women's Characterizations of Intimate Partner Interactions about Menopause." Journal of Women \& Aging 20 $(1 / 2): 47-64$.

- 2011. "Menopausal and Misbehaving: When Women 'Flash' in Front of Others." In Embodied Resistance: Breaking the Rules in Public Spaces, edited by Chris Bobel and Samantha Kwan, 197-208. Nashville, TN: Vanderbilt University Press.

- 2012. "Reproductive History as Social Context: Exploring How Women Converse about Menopause and Sexuality at Midlife." In Sex for Life: From Virginity to Viagra, How Sexuality Changes Throughout Our Lives, edited by John DeLamater and Laura Carpenter, 217-35. New York: New York University Press.

Dillaway, Heather, and Jean Burton. 2011. "Not Done Yet?! How Women Discuss the 'End' of Menopause." Women's Studies: An Interdisciplinary Journal 40 (2): 149-76.

Dinnerstein, Myra, and Rose Weitz. 1994. "Jane Fonda, Barbara Bush, and Other Aging Bodies: Femininity and the Limits of Resistance." Feminist Issues 14: 3-24.

Fahs, Breanne. 2011. "Sex during Menstruation: Race, Sexual Identity, and Women's Accounts of Pleasure and Disgust." Feminism \& Psychology 21, no. 2 (May): $155-78$.

Fausto-Sterling, Anne. 1992. Myths of Gender. Revised edition. New York: Basic Books.

Featherstone, Michael, and Michael Hepworth. 1991. "The Mask of Ageing and the Postmodern Life Course." In The Body: Social Process and Cultural Theory, edited by Michael Featherstone, Michael Hepworth, and Bryan S. Turner, 371-89. London: Sage.

Grambs, Jean Dresden. 1989. Women Over Forty: Visions and Realities. Vol. 4. New York, NY: Springer.

Gray, F. du Plessix. 1996. "The Third Age: At a Certain Point, a Woman May Find That Men Stop Looking at Her and Start Listening to Her." The New Yorker, March 26, 186-91.

Hall, Lynne L. 1999. “Taking Charge of Menopause.” FDA Consumer 33 (6): 17.

Harlow, Sioban D., Ellen S. Mitchell, Sybil Crawford, Bin Nan, Roderick Little, John Taffe, and ReSTAGE Collaboration. 2008. "The ReSTAGE Collaboration: Defining Optimal Bleeding Criteria for Onset of Early Menopausal Transition." Fertility and Sterility 89 (1): 129-40.

Hyde, Abbey, Jean Nee, Etaoine Howlett, Jonathan Drennan, and Michelle Butler. 2010. "Menopause Narratives: The Interplay of Women's Embodied Experiences with Biomedical Discourses." Qualitative Health Research 20 (6): 805-15.

Jarrell, Anne. 1999. "Noticed; Models, Defiantly Gray, Give Aging a Sexy New Look." New York Times, November 28. Accessed at http://www.nytimes. com/1999/11/28/style/noticed-models-defiantly-gray-give-aging-a-sexy-newlook.html.

Kafanelis, Betty V., Marion Kostanski, Paul A. Komesaroff, and Lily Stojanovska. 2009. "Being in the Script of Menopause: Mapping the Complexities of Coping Strategies." Qualitative Health Research 19, no. I (January): 30-41.

Lock, Margaret. 1993. Encounters with Aging: Mythologies of Menopause in Japan and North America. Berkeley, CA: University of California Press. 
Lyons, Antonia C., and Christine Griffin. 2003. "Managing Menopause: A Qualitative Analysis of Self-Help Literature for Women at Midlife." Social Science \& Medicine 56 (8): 1629-42.

Mansfield, Phyllis Kernoff, Molly Carey, Amy Anderson, Susannah Heyer Barsom, and Patricia Bartholow Koch. 2004. "Staging the Menopausal Transition: Data from the TREMIN Research Program on Women's Health." Women's Health Issues 14 (6): 220-26.

Mansfield, Phyllis Kernoff, Patricia Barthalow Koch, and Gretchen Gierach. 2003. "Husbands' Support of Their Perimenopausal Wives." Women \& Health 38 (3): 97-112.

Martin, Emily. 1992. The Woman in the Body: A Cultural Analysis of Reproduction. 2nd ed. Boston, MA: Beacon Press.

McElmurry, Beverly J., and Donna S. Huddleston. 1991. "Self-Care and Menopause: Critical Review of Research." Health Care for Women International 12 (1): 15-26.

Meyer, Vicki. 2003. "Medicalized Menopause, US Style." Health Care for Women International 24 (9): 822-30.

Muhlbauer, Varda, and Joan C. Chrisler, eds. 2007. Women Over 50: Psychological Perspectives. New York: Springer Science \& Business Media.

Niland, Patricia, and Antonia C. Lyons. 2011. "Uncertainty in Medicine: Meanings of Menopause and Hormone Replacement Therapy in Medical Textbooks." Social Science \& Medicine 73 (8): 1238-45.

Prior, Jerilynn C. 2005. "Ovarian Aging and the Perimenopausal Transition." Endocrine 26 (3): 297-300.

Reid, Anne. 2004. "Gender and Sources of Subjective Well-Being." Sex Roles 51 (1112): 617-29.

Schwarzer, Ralf, and Benicio Gutierrez-Dona. 2005. "More Spousal Support for Men Than for Women: A Comparison of Sources and Types of Support.” Sex Roles 52 (7-8): 523-32.

Utz, Rebecca L. 2011. "Like Mother, (Not) Like Daughter: The Social Construction of Menopause and Aging." Journal of Aging Studies 25 (2): 143-54.

Vigeta, Sônia Maria Garcia, Helena Hachul, Sergio Tufik, and Eleonora Menicucci de Oliveira. 2012. "Sleep in Postmenopausal Women." Qualitative Health Research 22 (4): 466-75.

Walter, Carolyn Ambler. 2000. "The Psychosocial Meaning of Menopause: Women's Experiences." Journal of Women \& Aging 12 (3-4): 117-31.

Weed, Susun S. 1999. "Menopause and Beyond: The Wise Woman Way." Journal of Nurse-Midwifery 44 (3): 267-279.

Wilson, Robert A. 1966. Feminine Forever. New York: Evans and Co. (distributed by J.B. Lippincott).

Winterich, Julie A. 2007. "Aging, Femininity, and the Body: What Appearance Changes Mean to Women with Age." Gender Issues 24 (3): 51-69.

Winterich, Julie A., and Debra Umberson. 1999. "How Women Experience Menopause: The Importance of Social Context." Journal of Women \& Aging 11 (4): 57-73.

Zones, Jane Sprague. 2005. "Beauty Myths and Realities and Their Impact on Women's Health." In Understanding Society: An Introductory Reader edited by Margaret L. Andersen, Kim Logio, and Howard Taylor, 353-60. Belmont, CA: Thomson Learning, Inc. 
Open Access This chapter is licensed under the terms of the Creative Commons Attribution 4.0 International License (http://creativecommons.org/licenses/ by $/ 4.0 /$ ), which permits use, sharing, adaptation, distribution and reproduction in any medium or format, as long as you give appropriate credit to the original author(s) and the source, provide a link to the Creative Commons license and indicate if changes were made.

The images or other third party material in this chapter are included in the chapter's Creative Commons license, unless indicated otherwise in a credit line to the material. If material is not included in the chapter's Creative Commons license and your intended use is not permitted by statutory regulation or exceeds the permitted use, you will need to obtain permission directly from the copyright holder. 